\title{
Evolving Technology
}

\section{Three-dimensional echo-guided beating heart surgery without cardiopulmonary bypass: Atrial septal defect closure in a swine model}

\author{
Yoshihiro Suematsu, MD, PhD, ${ }^{a}$ Joseph F. Martinez, DVM, ${ }^{\text {a }}$ Benjamin K. Wolf, BS, ${ }^{\text {b }}$ Gerald R. Marx, MD, \\ Jeffrey A. Stoll, BS, ${ }^{\text {b }}$ Pierre E. DuPont, PhD, ${ }^{b}$ Robert D. Howe, PhD, ${ }^{\mathrm{c}}$ John K. Triedman, MD, ${ }^{a}$ \\ and Pedro J. del Nido, MD
}

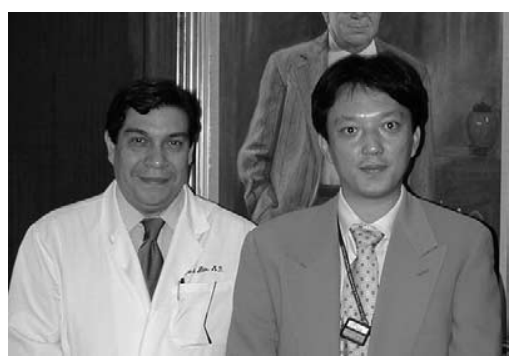

Drs del Nido and Suematsu

\footnotetext{
From the Departments of Cardiac Surgery and Cardiology, Children's Hospital and Harvard Medical School, ${ }^{\mathrm{a}}$ Boston, Mass, the Department of Aerospace and Mechanical Engineering, Boston University, ${ }^{\mathrm{b}}$ Boston, Mass, and the Division of Engineering and Applied Sciences, Harvard University, ${ }^{\mathrm{C}}$ Cambridge, Mass.

This study was supported in part by National Institutes of Health grant HL71128 and HL 73647 (P.J.D.) and by the Japan Society for the Promotion of Science (Y.S.).

Read at the Eighty-fifth Annual Meeting of The American Association for Thoracic Surgery, San Francisco, Calif, April 10-13, 2005.

Received for publication March 28, 2005; revisions received June 20, 2005; accepted for publication June 28, 2005

Address for reprints: Pedro J. del Nido, MD, Department of Cardiac Surgery, Children's Hospital-Boston, 300 Longwood Ave, Boston, MA 02115 (E-mail: pedro.delnido@tch.harvard.edu).

J Thorac Cardiovasc Surg 2005;130:1348-57 $0022-5223 / \$ 30.00$

Copyright (C) 2005 by The American Association for Thoracic Surgery

doi:10.1016/j.jtcvs.2005.06.043
}

Objective: In this study, we tested 3 techniques of atrial septal defect closure under real-time 3-dimensional echocardiography guidance in a swine model.

Methods: The operations were conducted under the sole guidance of a modified real-time 3-dimensional echocardiography guidance system with a $\times 4$ matrix transducer (Sonos 7500, Philips Medical Systems, Andover, Mass). Eighteen swine were anesthetized, and after median sternotomy, the echo probe was applied directly to the surface of the right atrium. To create an atrial septal defect, balloon atrial septostomy and atrial septal defect enlargement were performed. Subsequently, 3 different techniques of atrial septal defect closure were attempted: group I, direct suture closure; group II, closure of the atrial septal defect using the Amplatzer device (AGA Medical Corp, Golden Valley, Minn); and group III, patch closure of the atrial septal defect $(n=6$ each).

Results: Real-time 3-dimensional echocardiography guidance provided sufficient spatial resolution and a satisfactory frame rate to provide a "virtual surgeon's view" of the relevant anatomy during the entire procedure. All atrial septal defects were enlarged, and the mean final size was $8.5 \pm 1.8 \mathrm{~mm}$. Atrial septal defect closure was successfully accomplished with all the 3 surgical techniques examined. In groups I and III, the needles (1-3 sutures) and staples (6-12 staples) penetrated the tissue and patch material consistently, whereas in group III, the Amplatzer atrial septal defect device was easily deployed. There was no incident device/staple embolization or air introduction. Neither intraoperative 2-dimensional color Doppler echocardiography nor postmortem macro-evaluation revealed any residual shunts.

Conclusions: Beating heart atrial septal defect closure under real-time 3-dimensional echocardiographic guidance is feasible and, unlike catheter-based devices, applicable for any type of secundum atrial septal defect.

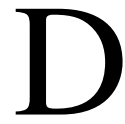
espite allowing direct visualization of intracardiac structures, cardiopulmonary bypass (CPB) has a number of adverse effects, including generation of microemboli and an inflammatory response associated with increased cytokine production and complement activation, which together can result in neurologic dysfunction in adults and neurodevelopmental dysfunction in children. ${ }^{1,2}$ 


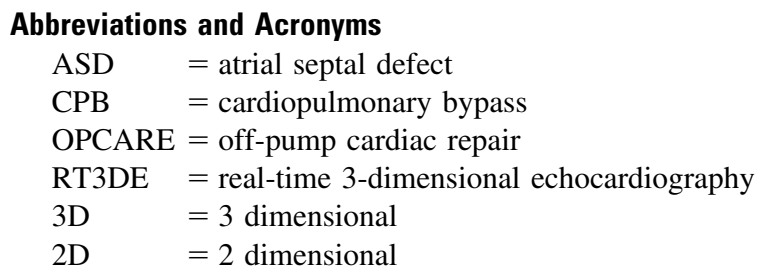

Furthermore, the long-term effects of CPB still remain unclear, and its deleterious effects may be more pronounced in infants than in patients of older age. Recently, investigators have attempted beating heart intracardiac surgery without $\mathrm{CPB} ;{ }^{3,4}$ however, the imaging systems used were deemed suboptimal for satisfactory visualization of the intracardiac structures.

Over the last 4 decades, echocardiography has evolved from single-beam imaging to sophisticated 3-dimensional (3D) techniques that enable study of the cardiac structures and functions, and the hemodynamics in great detail. ${ }^{5} \mathrm{Re}$ cently, real-time 3-dimensional echocardiography (RT3DE) was developed, which serves as a new modality for clinicians and surgeons for visualizing the heart noninvasively without electrocardiographic or respiratory gating. A new probe was developed that creates a fully sampled 2-dimensional (2D) array and allows 3D imaging with instantaneous on-line volume-rendered reconstruction, direct manipulation of thresholding, and planes cut on the ultrasound unit. This new 3D probe has great potential for expanded applications, not only for medical diagnosis but also for imageguided surgical intervention. We previously demonstrated that RT3DE provided adequate anatomic detail for surgicaltask performance in an in vitro model. ${ }^{6}$ In this study, we assessed the feasibility of 3 techniques for beating atrial septal defect (ASD) closure without $\mathrm{CPB}$ in a swine model.

\section{Materials and Methods \\ Echographic Equipment}

RT3DE was performed using the $\times 4$ matrix transducer on a Sonos 7500 system (Philips Medical Systems, Andover, Mass). The transducer operates in a broadband range of 2 to $4 \mathrm{MHz}$ and scans a $3 \mathrm{D}$ volume by electronically steering the acoustic beam using a matrix of approximately 3000 transducer elements and associated electronics that allow scanning of a $64^{\circ} \times 64^{\circ}$ pyramidal volume in real time at up to 28 frames per second. The Sonos 7500 base system volume renders the data in any viewing orientation desired, at a frame rate of $28 \mathrm{~Hz}$, and the orientation of the target object on the screen can be controlled with a rollerball. The image processing and rendering platform is based on a dual $2.2 \mathrm{GHz}$ Pentium 4 processor PC, which supports multiple imaging modalities, including conventional B-mode 2D echo, 2D color flow Doppler imaging, biplanar $2 \mathrm{D}$ echo, and several real-time volume rendering modes.

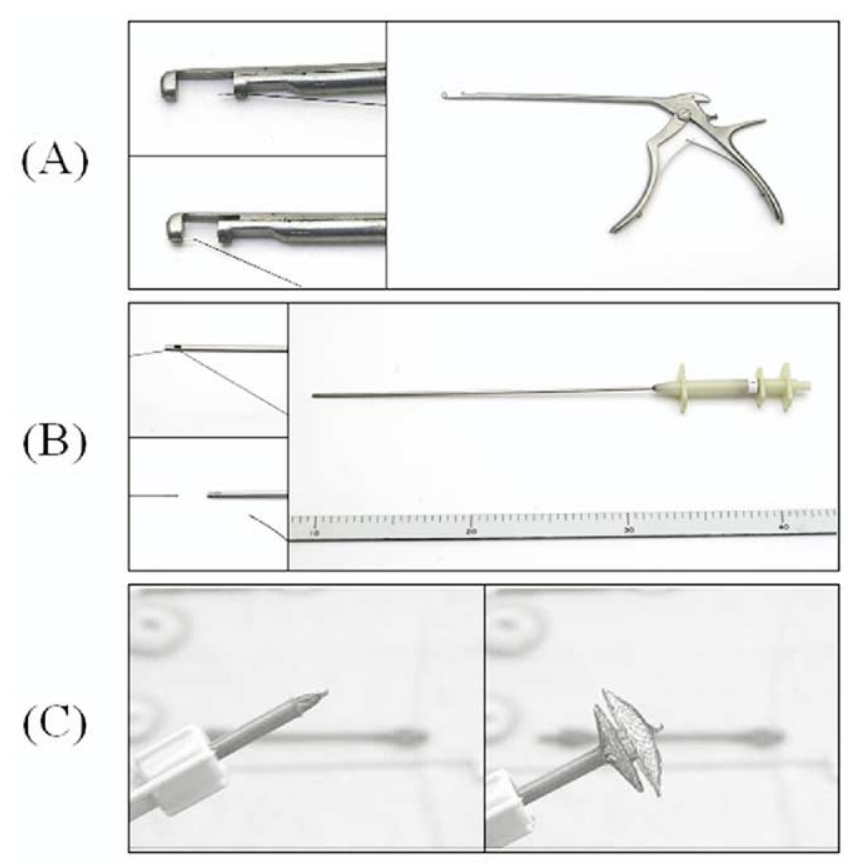

(D)

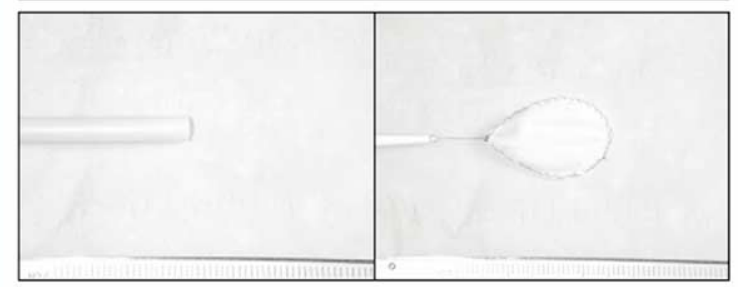

(E)

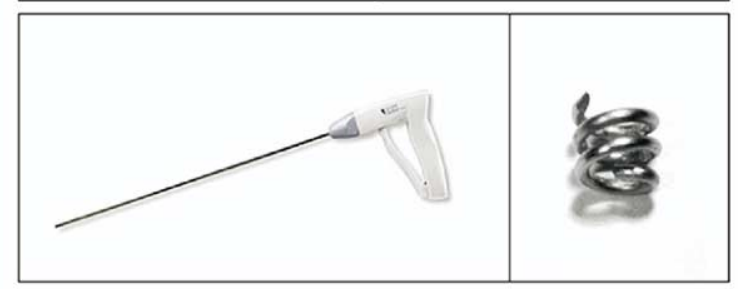

Figure 1. A, Semiautomatic suturing device. B, Suture cutting device. C, Amplatzer ASD device (AGA Medical Corp, Golden Valley, Minn). D, Patch-deployment device. E, Endoscopic stapler (Tacker, Autosuture, Norwalk, Conn).

\section{Surgical Devices}

A semiautomatic suturing device developed by us for off-pump intracardiac surgery was used as previously described (Figure 1, A). ${ }^{7,8}$ In brief, a needle with a conical point is threaded with 4-0 silk thread. The base of the needle is affixed in a niche on the tip of the proximal jaw of the semiautomatic suture device by pulling the thread down with 1 hand. The jaws close after the needle is passed through the tissue to be fixed. When the jaw is slowly opened again, the tip of the needle is automatically grasped by the distal jaw, which has a resilient slit. When the device is gently moved off the tissue, it is ensured that the thread has penetrated the tissue appropriately. After the device is pulled out of the cardiac cavity with the needle, the same action is repeated for the opposing 
edge of tissue. The device is $5 \mathrm{~mm}$ in diameter. A commercially available knot pusher (Olympus Co, Tokyo, Japan) was used for suture ligation in minimally invasive cardiac surgery. A suture cutting device consisting of a shaft, cutting edge, and handle was used to cut the sutures (Figure 1,B). ${ }^{8}$ The shaft of this device consists of an inner and outer tube, and the outer diameter of the outer tube is $2.5 \mathrm{~mm}$. The inner shaft has the cutting edge, which is used to insert and cut the thread. The handle is connected to the end of the shaft and is used to turn the inner tube. The thread is cut by placing it between the inner and the outer cutting edge.

In addition to the semiautomatic suturing device described, we used a commercially available endoscopic stapler (Tacker, Autosuture, Norwalk, Conn) that has a shaft $5 \mathrm{~mm}$ in diameter, which delivers spiral titanium tacks, and a multiuse handle, which allows surgical approximation (Figure 1,E).

We also used the Amplatzer ASD device (AGA Medical Corp, Golden Valley, Minn) for the ASD closure (Figure 1, C). In brief, this device is made of a Nitinol wire mesh, and the wires are shaped to form double discs with a short connecting waist. Dacron is sewn inside the discs with a polyester thread to increase its closing ability. A female screw is welded to the center of the right disc for attachment to the delivery cable. Because the device can be easily rotated at the time of deployment, a simple delivery sheath is used for the deployment. For patch closure of the ASD, an original-design patch-opener device, consisting of a selfexpanding ring of nitinol and a grip, was used (Figure $1, D) .{ }^{6} \mathrm{~A}$ 0.1-mm polytetrafluoroethylene patch (Gore-Tex, W. L. Gore \& Associates, Inc, Flagstaff, Ariz) was appropriately trimmed, and then sutured along the ring with 6-0 Prolene (Ethicon Inc, Somerville, NJ). This device is delivered through a long sheath $(5 \mathrm{~mm}$ in diameter), and the nitinol ring with the patch is advanced through the end of the sheath and allowed to expand.

\section{ASD Closure}

All animals received humane care in compliance with the "Principles of Laboratory Animal Care," prepared by the National Society for Medical Research, and the "Guide for the Care and Use of Laboratory Animals," prepared by the Institute of Laboratory Animal Resources and published by the National Institutes of Health (NIH publication no. 86-23, revised in 1985).

Twenty-one swine weighing $73.7 \pm 5.8 \mathrm{~kg}$ were used. Anesthesia was induced in the animals by intramuscular injection of tiletamine/zolazepam $(7 \mathrm{mg} / \mathrm{kg})$ and xylazine $(4 \mathrm{mg} / \mathrm{kg})$, and after the animals were intubated with a cuffed endotracheal tube, anesthesia was maintained with $2 \%$ isoflurane. Each animal was ventilated at a peak inspiratory pressure of $20 \mathrm{~cm} \mathrm{H}_{2} \mathrm{O}$, an inspired oxygen fraction of 0.21 , and a respiratory rate of 10 to 20 breaths/min, with a pressure-control type ventilator (Healthdyne model 105; Healthdyne Technologies, Marietta, Ga). The electrocardiogram was continuously monitored throughout the procedure. A median sternotomy was performed; the right atrium was suspended upward with a few stay sutures, and the echocardiographic transducer was directly applied to its surface. Figure 2 shows the schema of the operation. Our previous water-tank experiment demonstrated that the best images were obtained with the ultrasonic transducer at distances of 4 to $6 \mathrm{~cm}$ from the target. ${ }^{6}$ Therefore, where necessary, a stand-off was placed between the transducer and the right atrium to optimize the image and range of the field. A purse-string suture of 3-0 polypropylene was placed around the right atrial appendage, and in the group undergoing patch closure of the ASD, another additional purse-string suture for insertion of the patch was placed below the superior vena cava in the right atrium.

Three surgical maneuvers were performed through the pursestring suture after intravenous heparin administration of $100 \mathrm{U} / \mathrm{kg}$. The surgeon operated solely under ultrasonic guidance. First, a balloon catheter was inserted across the fossa ovalis, and after balloon atrial septectomy, the atrial communication was enlarged with a Kerrison bone punch. Then, the ASD was carefully closed using 1 of the following 3 techniques: (1) interrupted suture closure with the suture device (each suture was tied with a knot pusher and the threads were cut using a suture cutting system) (2) closure with an Amplatzer ASD device; or (3) patch closure using the endoscopic stapler and patch-opener device. Echocardiography with color Doppler interrogation was used to confirm ASD closure and to detect any residual shunt. Finally, the heart was excised and the efficacy of closure and patch or suture fixation was confirmed.

After ASD closure was accomplished, the residual atrial shunt was graded by 2D epicardial echocardiography, as previously described $^{9}$ : (1) none, no defect as visualized by $2 \mathrm{D}$ echo and no color Doppler disturbance on the right atrial side; (2) trivial, no defect by $2 \mathrm{D}$ echo and minimal color disturbance on the right atrial side ( $<1 \mathrm{~mm}$ width at origin of the color Doppler jet); (3) small, no defect by $2 \mathrm{D}$ echo and 1 to $2 \mathrm{~mm}$ width at the origin of the color Doppler jet; (4) moderate, defect visualized on 2D echo and more than $2 \mathrm{~mm}$ width at the origin of the color jet; or (5) large, defect visualized by $2 \mathrm{D}$ echo and large and/or multiple color jets. Offpump ASD closure was considered to have been successfully accomplished when the residual atrial shunt was graded as none or trivial, all the sutures were tightly knotted, and no significant air bubbles were introduced into the cardiac cavity, as observed by echocardiography, during the procedure.

\section{Results \\ ASD Creation}

In all the animals, small ASDs were successfully created in the fossa ovalis by balloon atrial septostomy. The interatrial communication was confirmed in all the cases by $2 \mathrm{D}$ Doppler echocardiography. Figure 3 shows representative sequential images during atrial septectomy. The inter-atrial communication was successfully enlarged by biting off the rim of the ASD with a Kerrison bone punch. Such enlargement of the ASD was also confirmed by 2D Doppler echocardiography (Figure 3,C). These maneuvers were easily performed by RT3DE-guided assessment of the spatial relationship between the ASD and the peripheral structures within a few minutes. The mean size of the ASD created was $8.5 \pm 1.8 \mathrm{~mm}(6-11 \mathrm{~mm})$ as visualized in the $2 \mathrm{D}$ color Doppler images.

The results for each procedure, including direct suture, device, and patch closure of the ASD, are summarized in Table 1. 


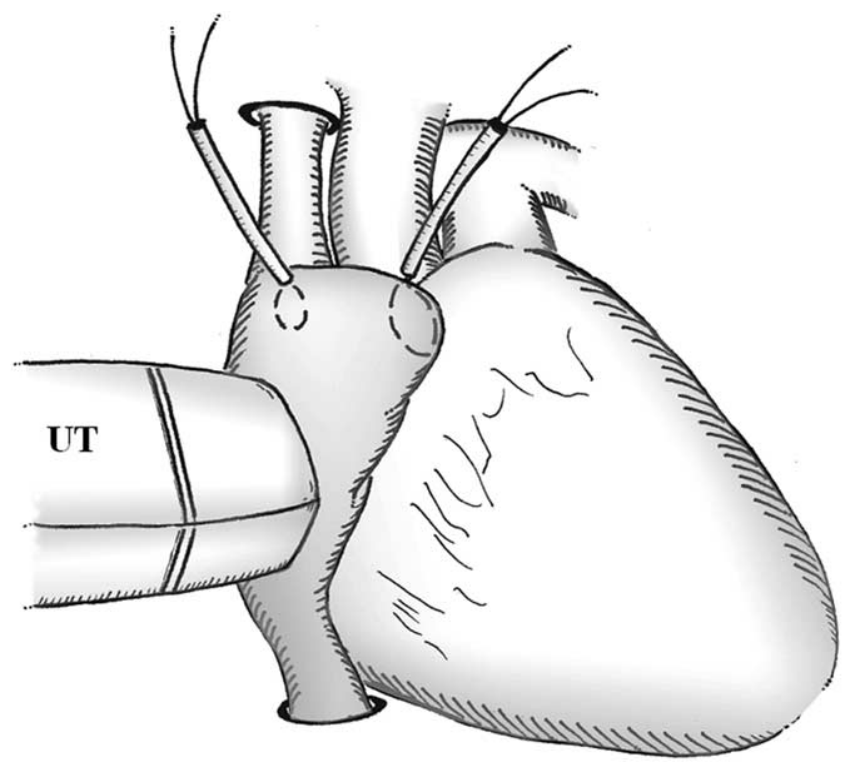

Figure 2. Intraoperative view. The ultrasound transducer is applied directly to the surface of the right atrium. All of the surgical devices were inserted through purse-string sutures on the right atrial appendage and right atrium. UT, Ultrasound transducer.

\section{Direct Suture Closure of ASD}

No changes in blood pressure or heart rate were noted during the intracardiac manipulations. Representative echo images of direct suture closure of the ASD are shown in Figure 4. After the ASD creation, this ASD was carefully closed with interrupted sutures using the suture device described, and each suture was tied with a knot pusher and the threads were cut using the suture cutting system. The ultrasound images were displayed just as the surgeon views an ASD from the right atrial side during an open procedure. In addition, the echo shadows produced on the surface of the atrial septal tissue by the instruments were found to be useful for recognizing the distance from the target even on the 2D images rendered by the echo system, consistent with our findings in a prior in vivo experiment. ${ }^{6}$ In regard to the surgical maneuvering, the suture passed through the rim of ASD was clearly visualized. Figure $4, F$ represents the image obtained just after the ASD was closed and each suture was tied. The average number of sutures placed for the closure was $3.0 \pm 0.9$ (range: $2-4$ ). The residual shunt after the ASD closure was classified as none or trivial in all cases. There was no significant introduction of air into the right atrium during the procedure, and none was detected in the left atrium. After the heart was excised and the right atrium was opened, all the sutures were confirmed to be tightly knotted. All the sutures were also located within a permissible range.
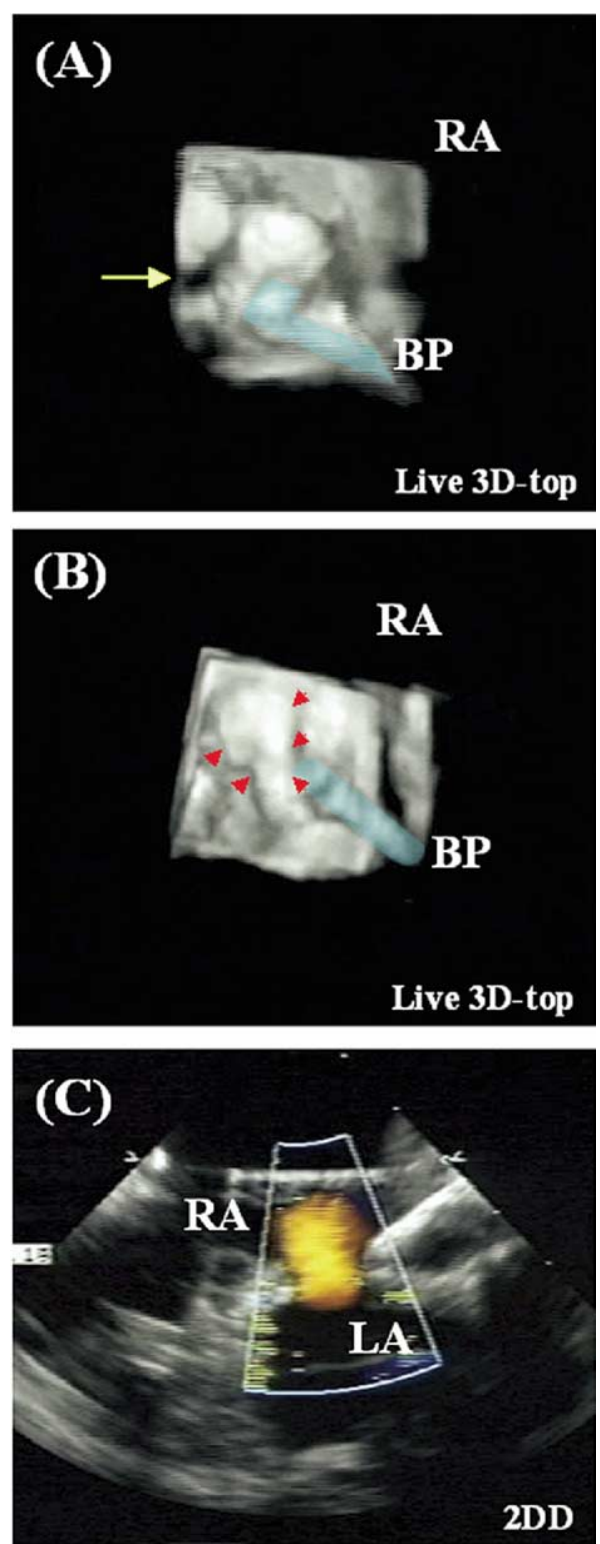

Figure 3. Real-time 3-dimensional echocardiographic (RT3DE) images showing atrial septal defect (ASD) enlargement with a Kerrison bone punch. For better comprehension, the device is shown in light blue. ASD (A) (yellow arrow). Deformed rim of the ASD grasped by Kerrison bone punch (B) (red arrows). C, Increased shunt flow through the enlarged ASD. $R A$, Right atrium; $L A$, left atrium; $B P$, Kerrison bone punch; live 3D, RT3DE image; 2DD, 2D Doppler echocardiographic image; top, view from the top.

\section{ASD Closure Using a Device}

Figure 5 shows representative sequential images obtained during deployment of the Amplatzer device. The sheath, at whose tip the device was loaded, was inserted through the purse-string suture on the right atrial appendage and ad- 
TABLE 1. Results

\begin{tabular}{|c|c|c|c|c|c|c|c|c|}
\hline Procedure & $\begin{array}{c}\text { Animal } \\
\text { No. }\end{array}$ & $\begin{array}{c}\text { ASD size } \\
(\mathrm{mm})\end{array}$ & $\begin{array}{c}\text { No. of } \\
\text { seizures }\end{array}$ & $\begin{array}{c}\text { Suture } \\
\text { deployment }\end{array}$ & Patch size (mm) & $\begin{array}{l}\text { Tissue } \\
\text { trauma }\end{array}$ & $\begin{array}{l}\text { Echo shunt after } \\
\text { closure }\end{array}$ & $\begin{array}{c}\text { Closure successful or } \\
\text { unsuccessful }\end{array}$ \\
\hline \multirow[t]{6}{*}{ Direct suturing } & 1 & 9 & 3 & + & - & None & None & S \\
\hline & 2 & 11 & 3 & + & - & None & None & $S$ \\
\hline & 3 & 9.5 & 2 & + & - & None & None & $S$ \\
\hline & 4 & 10 & 4 & + & - & None & Trivial & $S$ \\
\hline & 5 & 5 & 2 & + & - & None & None & $S$ \\
\hline & 6 & 10 & 4 & + & - & None & None & $S$ \\
\hline \multirow[t]{6}{*}{ Device closure } & 7 & 11 & - & $\mathrm{n} / \mathrm{a}$ & - & None & None & $S$ \\
\hline & 8 & 6 & - & $\mathrm{n} / \mathrm{a}$ & - & None & None & $S$ \\
\hline & 9 & 9.5 & - & $\mathrm{n} / \mathrm{a}$ & - & None & None & $S$ \\
\hline & 10 & 8 & - & $\mathrm{n} / \mathrm{a}$ & - & None & None & $S$ \\
\hline & 11 & 7 & - & $\mathrm{n} / \mathrm{a}$ & - & None & None & $S$ \\
\hline & 12 & 8 & - & $\mathrm{n} / \mathrm{a}$ & - & None & None & $S$ \\
\hline \multirow{6}{*}{ Patch closure } & 13 & 6 & 6 & + & 18 & None & None & $S$ \\
\hline & 14 & 10 & 12 & + & 20 & None & None & $S$ \\
\hline & 15 & 8 & 8 & + & 18 & None & None & $S$ \\
\hline & 16 & 7 & 7 & + & 18 & None & None & $S$ \\
\hline & 17 & 8 & 6 & + & 16 & None & Trivial & $S$ \\
\hline & 18 & 10 & 8 & + & 20 & None & None & $S$ \\
\hline
\end{tabular}

S, Successful; US, unsuccessful; n/a, not applicable, +/-, acceptable/not acceptable.

vanced into the ASD (Figure 5, A). The left disc was deployed in the left atrium, and the sheath and the disc were pulled back until the left disc approximated the atrial septum (Figure 5, B). The waist and the right disc were deployed while traction was maintained on the delivery cable (Figure 5, C). Proper position of the device was confirmed, and finally the device was released by rotating the delivery cable counterclockwise. None of the animals had any residual shunt after the ASD closure. There was no significant introduction of air into the right atrium during the procedure. Postmortem examination demonstrated that the device was appropriately fixed in the atrial septum.

\section{Patch Closure of the ASD}

Figure 6 shows representative sequential images obtained during patch closure of the ASD. The patch was inserted through an additional purse-string suture in the right atrium and advanced toward the ASD (Figure 6, A). Appropriate positioning of the patch was carefully confirmed from multiple views by manipulating a display control trackball that allows the operator to view the ASD and the patch from any angle without moving the transducer. Subsequently, the stapler was advanced through the purse-string suture on the right atrial appendage, and staples were deployed to approximate the patch and the atrial septum (Figure 6,C). Figure 6 ( $D$ and $E$ ) demonstrates the staples that fix the patch to the atrial septum from different angles. The stapler successfully penetrated both the tissue at the rim of the ASD and the patch material. Successful deployment of the coil was confirmed after the procedure. The size of the patch used was
$14.3 \pm 1.5 \mathrm{~mm}$ (range: $12-16 \mathrm{~mm}$ ), and the mean number of sutures was $7.8 \pm 2.2$ (range: $6-12$ ). The residual shunt after the ASD closure was classified as none or trivial, and all of the ASDs were successfully closed. Gross examination after excision of the heart showed that the patches were deployed in the appropriate positions in all the cases. The coils consistently penetrated the ASD tissue and the patch material. No collateral tissue injuries were observed in any of the cases.

\section{Discussion}

Secundum-type ASD is one of the most common cardiac anomalies occurring in isolation and accounts for between $5 \%$ and $15 \%$ of all congenital heart malformations. ${ }^{10}$ ASD was among the first of the cardiac anomalies to be corrected by operative treatment. In 1953, Gross and colleagues ${ }^{11}$ used an atrial well technique, and Lewis and Taufic ${ }^{12}$ successfully closed an ASD by using hypothermia and inflow occlusion. Sondergaard ${ }^{13}$ described his method of pursestring suture closure in 1954 . Nonetheless, when the very limited applicability of these methods became apparent, they were discarded. Gibbon ${ }^{14}$ started the era of ASD closure with open surgery, when he successfully repaired an ASD with CPB in a young woman. With subsequent technologic advances in CPB allowing safer and more reliable cardiac surgery, almost all surgeons have exclusively used CPB for ASD repair since the 1960s.

CPB has been widely recognized to have a number of deleterious effects, resulting in blood coagulation abnormalities, changes in erythrocyte and plasma proteins, and 

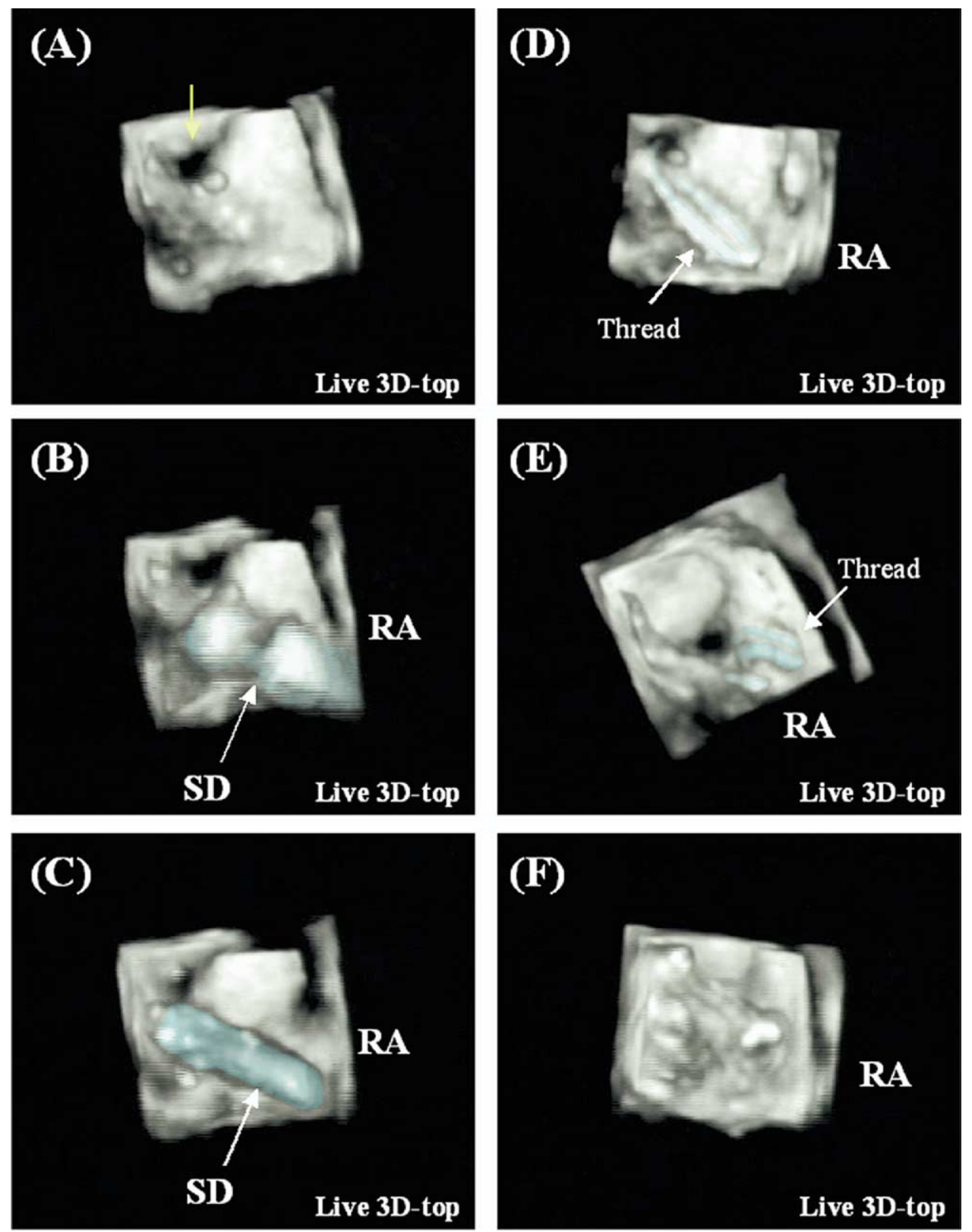

Figure 4. Sequential RT3DE images showing direct closure of the ASD with the semiautomatic suturing device. For better comprehension, the device and threads are shown in light blue. ASD (A) (yellow arrows). Interrupted sutures were carefully placed around the atrial septum $(B, C)$, and the threads were passed through the rim of the ASD (D,E). Each suture was tied with the knot pusher and the threads were cut using a suture cutting system (F). SD, Suturing device; $R A$, right atrium; live 3D, RT3DE image; 2DD, 2D Doppler echocardiographic image; side, view from the side; top, view from the top.

a nonspecific inflammatory response. Gas and particulate emboli, and various vasoactive and otherwise biologically active substances are also produced as a result of contact between blood and foreign surfaces during CPB, which can cause pulmonary, myocardial, and neurologic dysfunction. ${ }^{1,2}$
ASD closure in a beating heart without $\mathrm{CPB}$ has been performed by some surgeons and researchers. Warinsirikul and associates ${ }^{15}$ reported their clinical experience of 74 patients, in whom they successfully accomplished closure of ASD without CPB, thereby avoiding the adverse effects of CPB. They used a sandwich patch made of Teflon ma- 

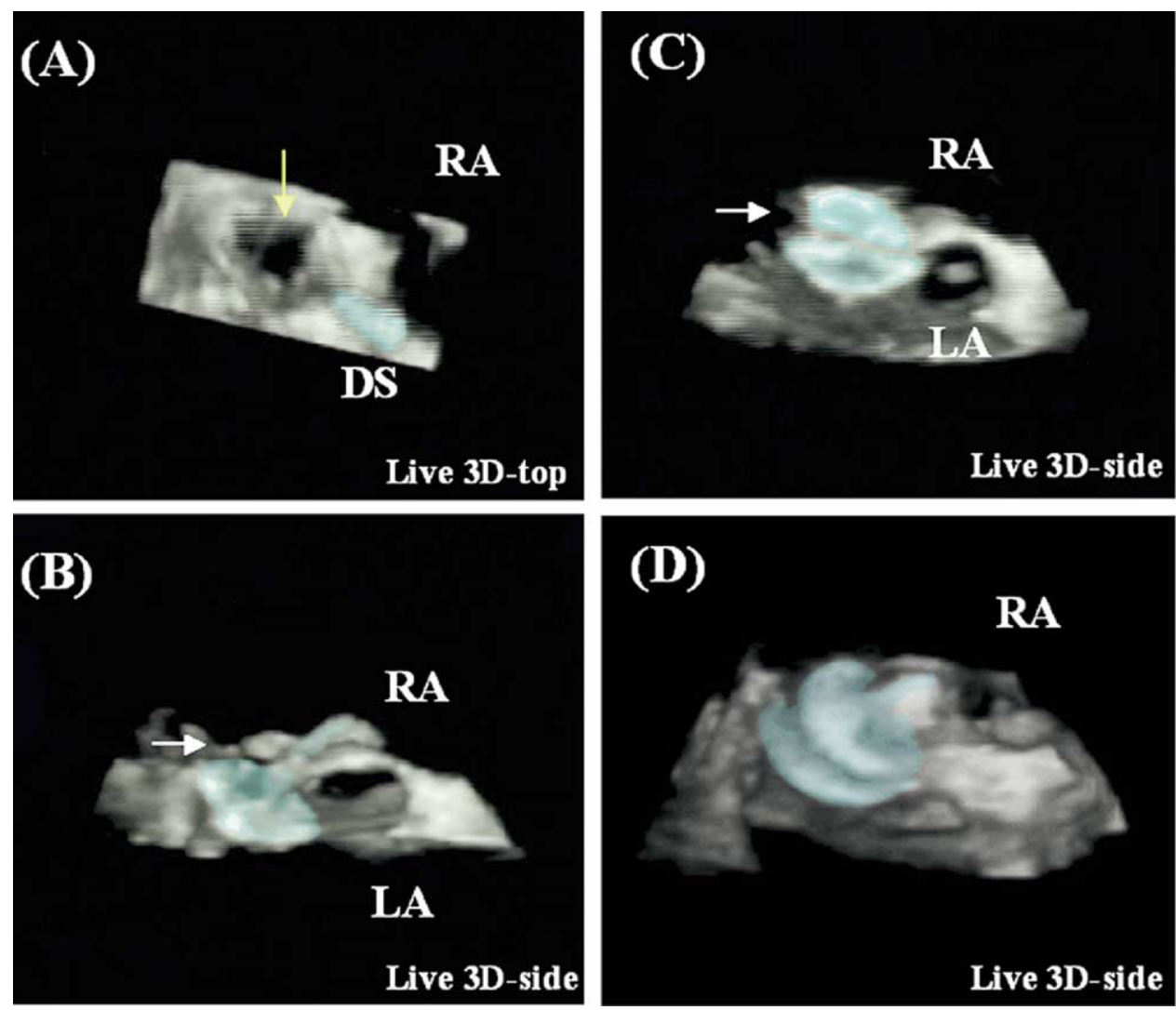

Figure 5. Sequential RT3DE images showing device closure of the ASD with an Amplatzer septal occluder. For better comprehension, the sheath and device are shown in light blue. ASD (yellow arrow). The sheath, with the device at the tip, was advanced into the ASD (A). The left disc was deployed in the left atrium (B), and the right disc was deployed in the right atrium (C,D). RA, Right atrium; $L A$, left atrium; $D S$, delivery sheath; live 3D, RT3DE image; side, view from the side; top, view from the top.

terial, which was passed into the right atrium through a purse-string suture and fixed with an endoscopic stapler. However, all the maneuvers were guided solely by the surgeon's index finger passed into the right atrium. Sogawa and associates ${ }^{3}$ reported closure of the foramen ovale without CPB using an intracardiac endoscope in a canine experiment. A glass tube with a round bottom $11 \mathrm{~mm}$ in diameter fixed with an endocardioscope was pushed against the luminal surface of the right atrium to visualize the foramen ovale at the center of the endocardioscope. A stapler $5.3 \mathrm{~mm}$ in diameter was used in this study; however, they found it impossible to conduct the stapling under endoscopic monitoring because of blood rushing into the space between the luminal surface and the glass tube as soon as the staple entered the atrial septum, necessitating blind stapling.

Downing and colleagues ${ }^{4}$ demonstrated beating-heart mitral valve suturing under 2D echocardiographic guidance. However, with 2D imaging guidance alone, it may not be possible to perform complex surgical interventions because spatial relationships cannot be assessed instantaneously. Also, obtaining favorable images in which both the target tissue and the surgical device can be monitored simultaneously is time-consuming, making it impractical to use this modality for real-time guidance. Other investigators have reported that despite the lower temporal and spatial resolution compared with conventional 2D images, operating under $3 \mathrm{D}$ echo guidance was superior to $2 \mathrm{D}$ for navigation. ${ }^{16}$ Our colleagues previously demonstrated that the completion time for simple surgical maneuvers was significantly decreased with 3D echo guidance compared with 2D echo guidance $(50 \%[P=.046]$ vs $77 \%[P=.009])$, with improved navigational accuracy $(46 \%, P=.040)^{17}$ comparable to endoscope-guided performance. We therefore consider that RT3DE allows a "surgeon's view" to be obtained in real time, enabling the surgeon to perform surgical interventions in the same manner as during endoscopic surgery.

Since the first successful attempt at per-catheter ASD closure by King and Mills in $1974,{ }^{18}$ a variety of devices 

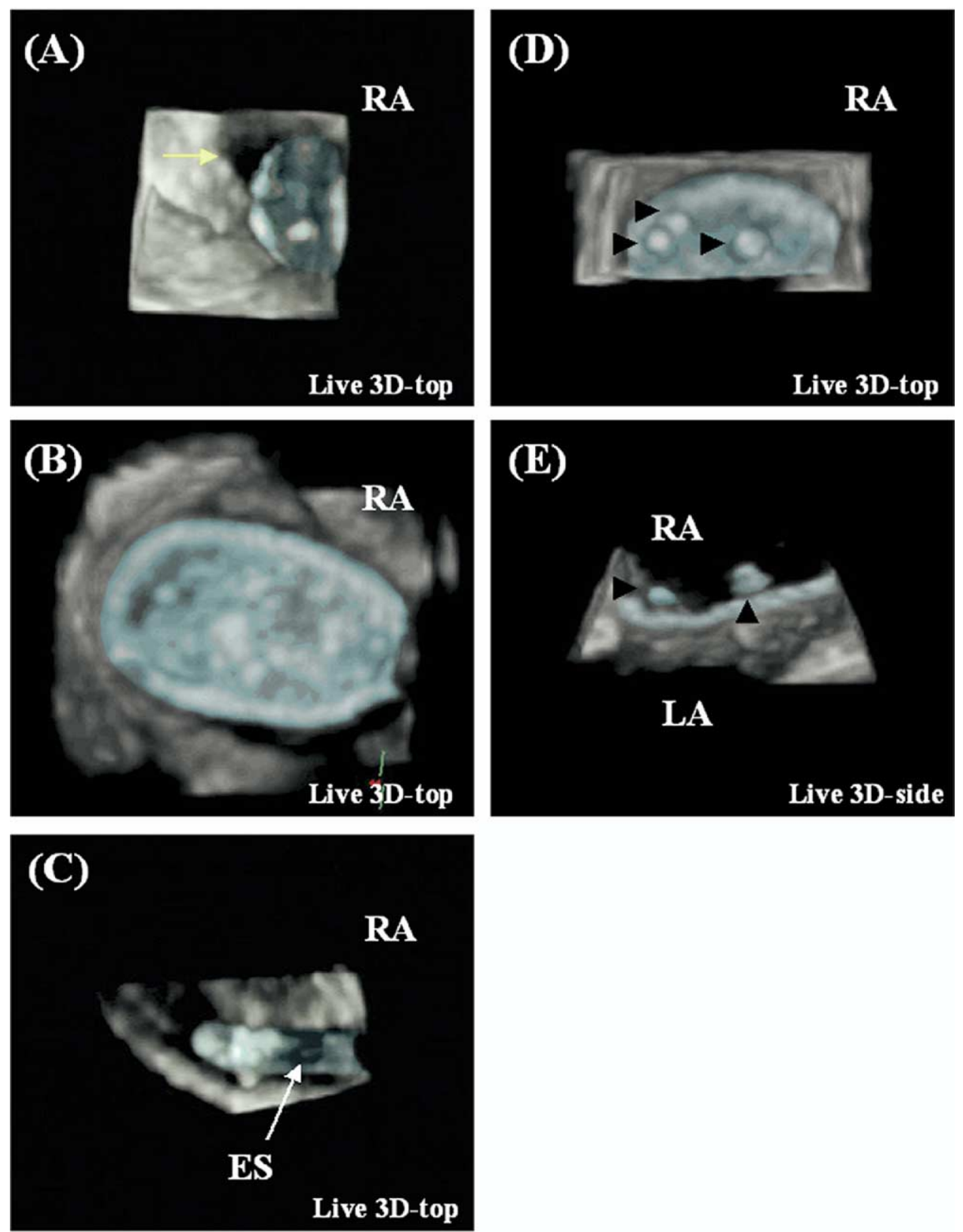

Figure 6. Sequential RT3DE images showing patch closure of the ASD with the patch-opener device and endoscopic stapler (SD). For better comprehension, the patch, staple, and endoscopic stapler are shown in light blue. ASD (yellow arrow). Staples placed on the patch (black arrowheads). The patch was advanced on the ASD (A,B). The stapler was advanced (C) and staples were placed to approximate the patch and the atrial septum (D,E). $R A$, Right atrium; $L A$, left atrium; ES, endoscopic stapler; live 3D, RT3DE image; side, view from the side; top, view from the top.

have been launched for transcatheter closure of ASDs. However, these devices are still associated with occasional complications. Poor patient selection (eg, those with very large defects), poor device selection (low ratio of device to defect), operator-related failure resulting from inadequate experience, and tearing of the interatrial septum especially at the lower rim of the ASD owing to catheter and device manipulation have been reported to result in acute failure of these devices. ${ }^{19,20}$ Furthermore, chronic/late failure has been reported owing to unbuttoning and fracture of the framework of the device, ${ }^{21}$ and thromboembolic episodes as a result of poor endothelialization of these devices, 
necessitating long-term use of anticoagulants or even surgical removal of the device. ${ }^{22}$ Berdat and colleagues ${ }^{23}$ reported from their clinical experience that surgery was required after transcatheter closure of an ASD or a patent foramen ovale in $8 \%$ of their patients. Therefore, if surgery could be accomplished through a smaller incision compared with that for conventional open surgery, and CPB is avoided, it may become an acceptable alternate approach to device closure.

There are some limitations of our study method. One is the difficulty of visualization of metallic surgical devices by echocardiography. Metallic devices frequently cause significant acoustic interference because of shadowing, side-lobe artifacts, and inconsistent tool appearance. Currently, the authors (J.A.S, P.E.D) are involved in developing a new surface coating for devices to make them compatible with ultrasound beams. Also, overlaying of the virtual configuration of the surgical device on the echo images by mounting a magnetic tracker system on the device may be another solution to aid in instrument navigation inside the heart. Second, the spatial resolution of RT3DE still needs to be optimized to advance its application from simulation into a clinical setting. Finally, the transducer is too large to be applied directly to the heart through a small incision because the operating field is restricted. To minimize the incision size for RT3DE-guided beating heart surgery, further technologic development advancements of the RT3DE system are mandatory.

\section{Conclusion}

The results in this study showed that beating heart intracardiac surgery can be performed under sole RT3DE guidance. We believe that 3D echo-guided beating-heart ASD closure is feasible, and that unlike catheter devices, it is applicable to any type of secundum ASD regardless of size or shape.

\section{References}

1. Zeitlhofer J, Asenbaum S, Spiss C, Wimmer A, Mayr N, Wolner E, et al. Central nervous system function after cardiopulmonary bypass. Eur Heart J. 1993;14:885-90.

2. Bellinger DC, Wypij D, Kuban KC, Rappaport LA, Hickey PR, Wernovsky G, et al. Developmental and neurological status of children at 4 years of age after heart surgery with hypothermic circulatory arrest or low-flow cardiopulmonary bypass. Circulation. 1999;100:526-32.

3. Sogawa M, Moro H, Tsuchida M, Shinonaga M, Ohzeki H, Hayashi J. Development of an endocardioscope for repair of an atrial septal defect in the beating heart. ASAIO J. 1999;45:90-3.

4. Downing SW, Herzog WA Jr, McLaughlin JS, Gilbert TP. Beatingheart mitral valve surgery: preliminary model and methodology. J Thorac Cardiovasc Surg. 2002;123:1141-6.

5. Naqvi TZ. Recent advances in echocardiography. Cardiovasc Ther. 2004;2:89-96.

6. Suematsu Y, Marx GR, Triedman JK, Mihaljevic T, Mora BN, del Nido PJ. 3-dimensional echo-guided beating-heart surgery without cardiopulmonary bypass: feasibility study. J Thorac Cardiovasc Surg. 2004;128:579-87.
7. Suematsu Y, Takamoto S. Semi-automatic suturing device for minimally invasive cardiac surgery. Kyobu Geka. 2003;56:203-6.

8. Suematsu Y, Takamoto S, Kaneko Y, Ohtsuka T, Takayama H, Kotsuka Y, et al. Beating atrial septal defect closure monitored by epicardial real-time three-dimensional echocardiography without cardiopulmonary bypass. Circulation. 2003;107:785-90.

9. Rao PS, Sideris EB, Hausdorf G, Rey C, Lloyd TR, Beekman RH, et al. International experience with secundum atrial septal defect occlusion by the buttoned device. Am Heart J. 1994;128:1022-35.

10. Benson LN, Freedom RM. Atrial septal defect. In: Freedom RM, Benson LN, Smallborn JF, editors. Neonatal heart disease. London: Springer-Verlag; 1992. p. 633-44.

11. Gross RE, Watkins E Jr, Pomeranz AA, Goldsmith EI. Method for surgical closure of interauricular septal defects. Surg Gynecol Obstet. 1953;96:1

12. Lewis FJ, Taufic M. Closure of atrial septal defect with aid of hypothermia. Surgery. 1953;33:52.

13. Sondergaard T. Closure of atrial septal defects: report of three cases. Acta Chir Scand. 1954;107:492.

14. Gibbon JH Jr. Application of a mechanical heart and lung apparatus to cardiac surgery. Minnesota Med. 1954;37:171-85.

15. Warinsirikul W, Sangchote S, Mokarapong P, Chaiyodsilp S, Tanamai S. Closure of atrial septal defects without cardiopulmonary bypass: the sandwich operation. J Thorac Cardiovasc Surg. 2001;121:1122-9.

16. Downing SW, Herzog WR, McElroy MC, Gilbert TB. Feasibility of off-pump ASD closure using real-time 3-D echocardiography. Heart Surg Forum. 2001;5:96-9.

17. Cannon JW, Stoll JA, Salgo IS, Knowles HB, Howe RD, Dupont PE, et al. Real-time 3-dimensional ultrasound for guiding surgical tasks. Computer Aided Surg. 2003;8:82-90.

18. King TD, Mills NL. Nonoperative closure of atrial septal defects. Surgery. 1974;75:383-8.

19. Gutti RS, Dronamraju D, Saha A. Operative findings in failed button device closure of ASD. Ann Thorac Surg. 1995;59:793-4.

20. Agarwal SK, Ghosh PK, Mittal PK. Failure of devices used for closure of atrial septal defects: mechanisms and management. $J$ Thorac Cardiovasc Surg. 1996;112:21-6.

21. Lloyed TR, Beekman RH. Transcatheter closure of atrial septal defect and patent ductus arteriosus. In: Topol EJ, editor. Textbook of interventional cardiology. 2nd ed. Philadelphia: WB Saunders; 1994. p. 1298-311.

22. Prewitt KC, Gaither NS, Farb A, Wortham DC. Transient ischemic attacks after long-term clamshell occluder implantation for closure of atrial septal defect. Am Heart J. 1992;124:1394-7.

23. Berdat PA, Chatterjee T, Pfammatter JP, Windecker S, Meier B, Carrel T. Surgical management of complications after transcatheter closure of an atrial septal defect or patent foramen ovale. J Thorac Cardiovasc Surg. 2000;120:1034-9.

\section{Discussion}

Dr Ludwig K. von Segesser (Lausanne, Switzerland). I congratulate Dr Suematsu for this excellent report. We performed a similar study in 2003, which can be found in Interactive Cardiovascular and Thoracic Surgery (2003;2:120-4) in the CTSNet journal collection. At that time we looked at working heart offpump cardiac repair, or so-called OPCARE, and we identified 2 major issues: visualization and instrumentation. For visualization we relied at that time on 2 different intravascular ultrasound systems that allowed for mental reconstruction of a 3D image. There can be no doubt that the 3D imaging that was presented here is a major progress compared with the previous techniques.

With regard to instrumentation, we relied on a computer motion robotic system, but no specifically designed devices were available for us. Thus again, this is major progress with regard to the devices that were available for this study and that have been developed in this context.

I have 3 questions. 
Dr Suematsu, can you tell us something about handling of blood loss that must have occurred with the purse string suture access?

Dr Suematsu. Thank you, Dr von Segesser. In this study, we used a conventional purse string suture for device entry under median sternotomy because this was the first step of our beating heart project. Fortunately, we did not encounter critical blood loss in this series. However, we are currently developing a 2-valved intracardiac port to prevent possible blood loss and air entry.

Dr von Segesser. Can you give us some indications with regard to the time required for completion of your 3 different procedure techniques?

Dr Suematsu. Although that depends on the ASD size, actual time to complete the procedure is less than 10 minutes for ASD direct suture closure and 1 minute for device closure, and 10 to 15 minutes for patch closure. We believe this is acceptable.
Dr von Segesser. Do you have any recommendations for capturing moving targets on the $3 \mathrm{D}$ echo, such as aortic valve leaflets?

Dr Suematsu. Unfortunately, we don't have any experience with the aortic valve. Another target is actually the mitral valve repair under real-time 3D echo guidance. In our preliminary study of beating heart mitral valve surgery through an apical ventricular approach, we could easily grasp the leaflet by endoscopic forceps because time resolution is very high. However, image quality of the mitral valve is critical for that purpose. The frequency range of the current $3 \mathrm{D}$ echo probe is 2 to $4 \mathrm{MHz}$ and quite low to visualize the leaflet in this setting. Therefore, a high-frequency real-time 3D echo probe is needed to go forward with this project.

Dr von Segesser. Thank you very much for your excellent work. 